\title{
Spatial pattern of chloroplast DNA variation of Cyclobalanopsis glauca in Taiwan and East Asia
}

\author{
SOPHIE S. F. HUANG, ${ }^{*}$ SHIH-YING HWANG† and TSAN-PIAO LIN* \\ *National Taiwan University, Department of Botany, Roosevelt Road, Section 4, Taipei, Taiwan 106, +Graduate Institute of \\ Biotechnology, Chinese Culture University, Yangmingshan, Taipei, Taiwan
}

\begin{abstract}
This study examined the spatial pattern of chloroplast DNA (cpDNA) variation in Cyclobalanopsis glauca (Thunb. ex Murray) Oerst. (Fagaceae) in 140 trees from Taiwan (25 populations), Japan (three), Ryukyus (two), Hong Kong (one) and Mainland China (one). By sequencing three cpDNA intergenic spacer fragments using universal primers (trnT-trnL, $t r n \mathrm{~V}-t r n \mathrm{M}$, including the $t r n \mathrm{~V}$ intron, and petG-trnP), we found a total of $1980 \mathrm{bp}$ and 15 polymorphic sites. Among them, 12 sites were caused by point mutation, and three resulted from insertion. This gives rise to a total of $13 \mathrm{cpDNA}$ haplotypes. The level of differentiation among the populations studied is relatively high $\left(G_{\mathrm{ST}}=0.612\right)$. Two ancestral haplotypes (A and B) are distributed widely in East Asia. Interestingly, all the derived cpDNA variations are found only in Taiwan but not in other areas. The Central Mountain Ridge (CMR) of Taiwan creates an unsurpassed barrier to the east-west gene flow of C. glauca. Among the populations on the west of $\mathrm{CMR}$, only three separated populations, Yangmingshan, Wushe and Chinshuiying, have high haplotype diversity, each consisting of sister haplotypes all mutated from the same ancestral haplotype. Thus, they have probably originated from de novo mutation after the last glaciation. This inference agrees with the observation that no spatial autocorrelation existed on the west side. Two unrelated dominant lineages on the east of the CMR (haplotypes D and F) showed significant spatial genetic structure. Estimate of $N_{\mathrm{ST}}-G_{\mathrm{ST}}$ was $-\mathbf{0 . 0 9 0}$ and differed significantly from zero. Thus at the local scale, the phylogeographical component of the genetic structure is significant on the east of the CMR. Accompanied by published palynological records of the last glaciation, this study suggests the possibility that these two types were colonized northward from the southeastern part of Taiwan. 'Star-like' genealogy is characterized, with all the haplotypes coalescing rapidly and as a general outcome of population expansion (Page \& Holmes 1998). A neutrality test also suggested a demographic expansion recovered from a bottleneck. We therefore inferred that the southeastern part of Taiwan might be a potential refugium for C. glauca.
\end{abstract}

Keywords: barrier, differentiation, haplotype, migration, mutation, subtropical tree

Received 29 March 2002; revision received 21 July 2002; accepted 1 August 2002

\section{Introduction}

Genetic lineages are often localized geographically and may share a common history, such as episodes of vicariance, routes of migrations, colonization and recent population expansions (Avise 1994). Such historical insights can be obtained by identifying the organelle DNA

Correspondence: Dr Tsan-Piao Lin. Fax: 886 (2) 2368 9564; E-mail: tpl@ccms.ntu.edu.tw variation, which are then overlaid upon a geographical frame, reflecting the spatiotemporal dynamics of the organism studied. This has been demonstrated especially in European oaks (Ferris et al. 1995; Dumolin-Lapegue et al. 1997; Ferris et al. 1998; Fineschi et al. 2000; Matyas \& Sperisen 2001). Maternally inherited markers in plants will generally reveal much more genetic structure than nuclear markers (Hare 2001). In most plants cytoplasmic genomes such as chloroplast and mitochondria are dispersed through seed; they are more suitable for the reconstruction 


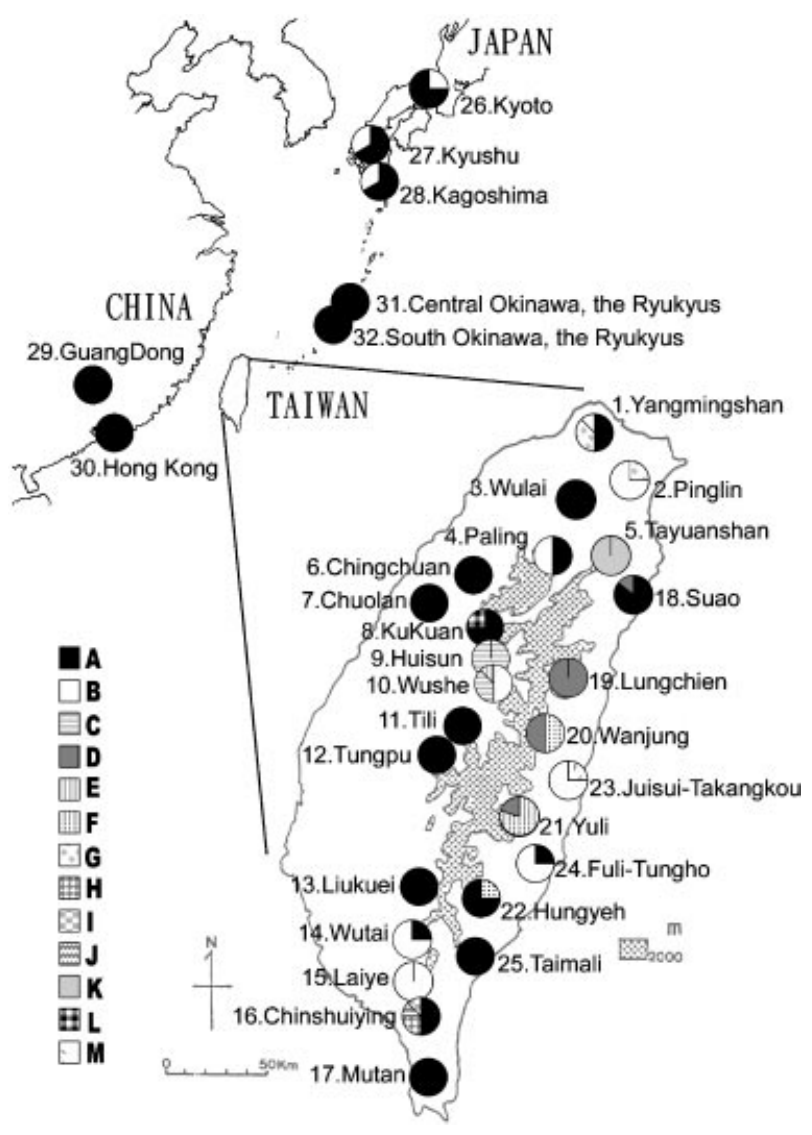

Fig. 1 Map of East Asia showing the location of the RyukyuTaiwan Archipelago, and the geographical distribution of the cpDNA haplotypes of Cyclobalanopsis glauca in Taiwan and East Asia. Only altitude above $2000 \mathrm{~m}$ of Central Mountain Ridge (CMR) was shown.

of past migrational patterns than nuclear genes, which are dispersed through both pollen and seed (McCauley 1995). Recent analyses of parentage in oaks, using hypervariable microsatellite nuclear markers, indicate extremely high levels of long-distance pollination and more limited acorn dispersal (Dow \& Ashley 1996).

Lying between the Asian continent and Philippine Sea basin, the island of Taiwan is commonly regarded geographically as a constituent of the island-arc system along the western edge of the Pacific Ocean. Geologically, this island connects the Ryukyu Island-arc to the north (Fig. 1) and the Philippine Island-arc to the south. The Central Mountain Ridge (CMR), the lofty backbone range runs basically following the axis of the island (see Fig. 1, the area above altitude of $2000 \mathrm{~m}$ ). Within this range are numerous peaks above $3000 \mathrm{~m}$ in elevation. The CMR of Taiwan has different effects on the genetic structure of different animal species; for example, Taipei treefrog (Yang et al. 1994), Indian rice frog (Toda et al. 1998), Formosan white-bellied rat (Hsu et al. 2000) and Formosan wood mouse (Hsu et al. 2001). These studies have indicated that phylogeographical structure existed in Taiwan. Limited studies, however, of phylogeography of plant species in East Asia have been published (Tomaru et al. 1998; Chiang et al. 2001; Huang et al. 2001; Lu et al. 2001). Cycas taitungensis (Huang et al. 2001) is extremely restricted to the southeast part of Taiwan, and Kandelia candel (Chiang et al. 2001) is restricted to several coast areas. The sampling sites for Cunninghamia konishii (Lu et al. 2001) were limited. Thus, these studies did not provide information concerning the phylogeographical structure of plant species within Taiwan.

Cyclobalanopsis glauca (previously Quercus glauca) is a widely distributed species of East Asia, and is the most commonly occurring plant among the 50 native species of the family Fagaceae in Taiwan. C. glauca is a mediumsized evergreen tree growing up to $20 \mathrm{~m}$ high, and $0.6 \mathrm{~m}$ in breast height diameter. The evergreen broad-leaved forests in Taiwan occurring at 400-2500 m consist of two types of forest: Machilus-Castanopsis and evergreen oak. A large number of tree species appear in these two forests, the most prominent among them belonging to the families Fagaceae and Lauraceae. C. glauca is found from sea level up to $1700 \mathrm{~m}$, and is one of the dominant species in the MachilusCastanopsis forests (Hsieh et al. 1994). No pure stand was found, but populations may form an aggregate on steep hillslope as one of the pioneer species. With respect to the usage of C. glauca, aboriginal people used it in construction, in mushroom culture and for making household items, such as wheel, various poles, etc. The only man-made plantations were established in mixed forests in selected sites in order to build a fire-deterring belt in areas with pine forests and a long dry season. Not only does it occur commonly; C. glauca was selected as material because the methodology and primers have been available and tested in numerous European species of Quercus.

A refugium area, however, has been proposed in Taiwan entirely from isozyme studies (Lin 2001). A thorough review of published papers on the genetic diversity of eight widely spread species led to the discovery that Nantou is the area with the highest expected heterozygosities, but this hypothesis has not been tested using DNA markers. Thus, this paper aims to address the following questions: (1) does the haplotype variation exhibit a random pattern or a geographical structure in Taiwan having a size of $36000 \mathrm{~km}^{2}$ ? (2) Do the major mountain systems have any impact on the distribution of genetic variation of organelle DNA markers? (3) How is the cpDNA variation of a subtropical tree species distributed in East Asia?

\section{Materials and methods}

\section{Sampling of plant populations}

Every stand used in this study was considered as genetically original, as low economic interest points strongly to their indigenous status. Leaves of Cyclobalanopsis glauca 
Table 1 Population numbers and locations of Cyclobalanopsis glauca sampled in this study

\begin{tabular}{|c|c|c|c|}
\hline Population & Location & Sampl sizes & Haplotypes (no. of individuals) \\
\hline 1. Yangmingshan, Taiwan & $121.51^{\circ} \mathrm{E}, 25.18^{\circ} \mathrm{N}$ & 8 & $A(4), B(1), G(3)$ \\
\hline 2. Pinglin, Taiwan & $121.70^{\circ} \mathrm{E}, 24.92^{\circ} \mathrm{N}$ & 4 & $B(3), G(1)$ \\
\hline 3. Wulai, Taiwan & $121.54^{\circ} \mathrm{E}, 24.86^{\circ} \mathrm{N}$ & 4 & $\mathrm{~A}(4)$ \\
\hline 4. Paling, Taiwan & $121.37^{\circ} \mathrm{E}, 24.68^{\circ} \mathrm{N}$ & 4 & $\mathrm{~A}(2), \mathrm{B}(2)$ \\
\hline 5. Tayuanshan, Taiwan & $121.67^{\circ} \mathrm{E}, 24.58^{\circ} \mathrm{N}$ & 4 & $\mathrm{~K}(4)$ \\
\hline 6. Chingchuan, Taiwan & $121.09^{\circ} \mathrm{E}, 24.58^{\circ} \mathrm{N}$ & 4 & $\mathrm{~A}(4)$ \\
\hline 7. Chuolan, Taiwan & $120.77^{\circ} \mathrm{E}, 24.33^{\circ} \mathrm{N}$ & 4 & $\mathrm{~A}(4)$ \\
\hline 8. KuKuan, Taiwan & $121.00^{\circ} \mathrm{E}, 24.21^{\circ} \mathrm{N}$ & 4 & $\mathrm{~A}(3), \mathrm{L}(1)$ \\
\hline 9. Huisun, Taiwan & $121.03^{\circ} \mathrm{E}, 24.09^{\circ} \mathrm{N}$ & 5 & $C(5)$ \\
\hline 10. Wushe, Taiwan & $121.13^{\circ} \mathrm{E}, 24.02^{\circ} \mathrm{N}$ & 8 & $\mathrm{~B}(4), \mathrm{C}(3), \mathrm{E}(1)$ \\
\hline 11. Tili, Taiwan & $120.95^{\circ} \mathrm{E}, 23.80^{\circ} \mathrm{N}$ & 4 & $\mathrm{~A}(4)$ \\
\hline 12. Tungpu, Taiwan & $120.91^{\circ} \mathrm{E}, 23.56^{\circ} \mathrm{N}$ & 4 & $\mathrm{~A}(4)$ \\
\hline 13. Liukuei, Taiwan & $120.64^{\circ} \mathrm{E}, 23.00^{\circ} \mathrm{N}$ & 4 & $\mathrm{~A}(4)$ \\
\hline 14. Wutai, Taiwan & $120.72^{\circ} \mathrm{E}, 22.74^{\circ} \mathrm{N}$ & 4 & $\mathrm{~A}(1), \mathrm{B}(3)$ \\
\hline 15. Laiye, Taiwan & $120.72^{\circ} \mathrm{E}, 22.52^{\circ} \mathrm{N}$ & 4 & $\mathrm{~B}(4)$ \\
\hline 16. Chinshuiying, Taiwan & $120.73^{\circ} \mathrm{E}, 22.42^{\circ} \mathrm{N}$ & 8 & $\mathrm{~A}(4), \mathrm{H}(2), \mathrm{I}(1), \mathrm{J}(1)$ \\
\hline 17. Mutan, Taiwan & $120.78^{\circ} \mathrm{E}, 22.13^{\circ} \mathrm{N}$ & 3 & $\mathrm{~A}(3)$ \\
\hline 18. Suao, Taiwan & $121.84^{\circ} \mathrm{E}, 24.60^{\circ} \mathrm{N}$ & 7 & $\mathrm{~A}(6), \mathrm{D}(1)$ \\
\hline 19. Lungchien, Taiwan & $121.43^{\circ} \mathrm{E}, 24.00^{\circ} \mathrm{N}$ & 5 & $\mathrm{D}(5)$ \\
\hline 20. Wanjung, Taiwan & $121.39^{\circ} \mathrm{E}, 23.72^{\circ} \mathrm{N}$ & 4 & $\mathrm{D}(2), \mathrm{F}(2)$ \\
\hline 21. Yuli, Taiwan & $121.25^{\circ} \mathrm{E}, 23.31^{\circ} \mathrm{N}$ & 5 & $\mathrm{D}(1), \mathrm{F}(4)$ \\
\hline 22. Hungyeh, Taiwan & $121.04^{\circ} \mathrm{E}, 22.90^{\circ} \mathrm{N}$ & 4 & $\mathrm{~A}(3), \mathrm{F}(4)$ \\
\hline 23. Juisui-Takangkou, Taiwan & $121.42^{\circ} \mathrm{E}, 23.50^{\circ} \mathrm{N}$ & 4 & $\mathrm{~B}(3), \mathrm{M}(1)$ \\
\hline 24. Fuli-Tungho, Taiwan & $121.27^{\circ} \mathrm{E}, 23.08^{\circ} \mathrm{N}$ & 4 & $\mathrm{~A}(1), \mathrm{B}(3)$ \\
\hline 25. Taimali, Taiwan & $121.01^{\circ} \mathrm{E}, 22.67^{\circ} \mathrm{N}$ & 3 & $\mathrm{~A}(3)$ \\
\hline 26. Kyoto, Japan & $135.78^{\circ} \mathrm{E}, 35.00^{\circ} \mathrm{N}$ & 4 & $\mathrm{~A}(1), \mathrm{B}(3)$ \\
\hline 27. Kyushu, Japan & $130.54^{\circ} \mathrm{E}, 33.67^{\circ} \mathrm{N}$ & 3 & $\mathrm{~A}(2), \mathrm{B}(1)$ \\
\hline 28. Kagoshima, Japan & $130.43^{\circ} \mathrm{E}, 31.55^{\circ} \mathrm{N}$ & 3 & $\mathrm{~A}(2), \mathrm{B}(1)$ \\
\hline 29. GuangDong, China & $113.25^{\circ} \mathrm{E}, 24.57^{\circ} \mathrm{N}$ & 2 & $\mathrm{~A}(2)$ \\
\hline 30. Hong Kong, China & $114.28^{\circ} \mathrm{E}, 22.32^{\circ} \mathrm{N}$ & 4 & $\mathrm{~A}(4)$ \\
\hline 31. Central Okinawa, Ryukyus & $127.97^{\circ} \mathrm{E}, 26.46^{\circ} \mathrm{N}$ & 4 & $\mathrm{~A}(4)$ \\
\hline 32. South Okinawa, Ryukyus & $127.69^{\circ} \mathrm{E}, 26.11^{\circ} \mathrm{N}$ & 4 & $\mathrm{~A}(4)$ \\
\hline
\end{tabular}

Table 2 Primer pairs for chloroplast DNA used in this study

\begin{tabular}{|c|c|c|c|c|}
\hline Primer pairs & $\begin{array}{l}\text { Template } \\
\text { DNA (ng) }\end{array}$ & $\begin{array}{l}\text { Annealing } \\
\text { temp }\left({ }^{\circ} \mathrm{C}\right)\end{array}$ & $\begin{array}{l}\text { Extention } \\
\text { time (s) }\end{array}$ & $\begin{array}{l}\text { Length } \\
\text { (bp) }\end{array}$ \\
\hline $\begin{array}{l}\text { trnT CATTACAAATGCGATGCTCT } \\
\text { trnL TCTACCGATTTCGCCATATC }\end{array}$ & 20 & 62 & 50 & $831-853$ \\
\hline $\begin{array}{l}\text { TrnV GCTATACGGGCTCGAACC (in exon 1) } \\
\text { trnM TACCTACTATTGGATTTGAACC }\end{array}$ & 0.04 & 60 & 50 & 811 \\
\hline $\begin{array}{l}\text { petG GGTCTAATTCCTATAACTTTGGC } \\
\text { trnP GGGATGTGGCGCAGCTTGG }\end{array}$ & 4 & 61 & 30 & 319 \\
\hline
\end{tabular}

from 140 trees were collected from 25 populations in Taiwan, three populations in Japan, two in the Ryukyus, one in Hong Kong and one in Mainland China from January 2001 to February 2002 (Table 1). We analysed four individuals for each population because it was shown that 2.5 individuals per population yield the minimum variance for $G_{\mathrm{ST}}$ at haploid locus regardless of the number of populations studied (Pons \& Petit 1995). DNA was extracted from leaves following modification of a standard protocol (Murray \& Thompson 1980).

\section{Polymersae chain reaction (PCR) and sequencing}

PCR was used to isolate specific intergenic spacers and the intron (noncoding region) of cpDNA. Three different pairs of universal primers were used (Table 2), as described by 
Taberlet et al. (1991) and Hwang et al. (2000). When testing the amplification condition, the PCR solution was mixed as follows: $500 \mathrm{~mm} \mathrm{KCl}, 15 \mathrm{~mm} \mathrm{MgCl}, 0.01 \%$ gelatin, $100 \mathrm{~mm}$ Tris-HCl (pH 8.3), $250 \mu \mathrm{M}$ of each dNTP, $2 \mu \mathrm{M}$ of each primer, 0.04-20 ng of template DNA (Table 2), $1 \mu \mathrm{g}$ RNase, 0.5 unit Taq polymerase (Amersham Pharmacia Biotech, Taiwan) and double-distilled water to a final volume of $10 \mu \mathrm{L}$. Amplifications were performed with an initial denaturing of $5 \mathrm{~min}$ at $95^{\circ} \mathrm{C}$ followed by 35 cycles of $45 \mathrm{~s}$ at $95^{\circ} \mathrm{C}, 30 \mathrm{~s}$ at $60-62{ }^{\circ} \mathrm{C}, 30 \mathrm{~s}$ or $50 \mathrm{~s}$ at $72{ }^{\circ} \mathrm{C}$ (Table 2) and ending with a 10-min extension at $72{ }^{\circ} \mathrm{C}$. The PCR products were purified using GFX PCR DNA and the Gel Band Purification Kit (Amersham Pharmacia Biotech). Nucleotide sequences were determined by direct sequencing of the purified PCR products on the ABI 3100 Genetic Analyser with BigDye terminator cycle sequencing reagents (Applied Biosystems). Precautions were taken to prevent any sequencing mistakes. When the PCR products were sequenced, an unexpected specific point mutation might appear in the population. In this case the individual was resequenced to verify the existence of the point mutation in the DNA sequence.

\section{Sequence analysis}

DNA sequences were aligned by eye with the BioEdit program. We deleted the exon sequences immediately following the six primers, the trn $\mathrm{V}$ exon 2 sequence within the $\operatorname{trn} \mathrm{V}-t r n \mathrm{M}$ fragment, and the $\operatorname{trn} \mathrm{W}$ gene sequence within the petG-trnP fragment. Construction of haplotypes and the estimation of gene genealogy using the less conservative intergenic spacers and intron in cpDNA were then performed by TCS version 1.06, as described by Templeton et al. (1992). Nucleotide diversity $(\pi)$, haplotype diversity $(h)$, tests of neutrality and the determination of their associated significance were performed using the DnaSP program (Rozas \& Rozas 1999).

\section{Analyses of population substructure}

Two measures of diversity and differentiation were analysed by Hapstep in this study (Pons \& Petit 1996). In the first analysis, each haplotype was treated as a separate allele at a single haploid locus. The average intrapopulation diversity $\left(H_{\mathrm{S}}\right)$, total diversity $\left(H_{\mathrm{T}}\right)$ and degree of substructure $\left(G_{\mathrm{ST}}\right)$ were calculated using procedures appropriate for haploid loci (Pons \& Petit 1995). In the second analysis the distances, $p_{i j}$, between haplotypes (expressed as numbers of mutational steps separating the $i$ th and $j$ th haplotype and normalized by the average pairwise number of mutational steps in the overall sample of haplotypes) were calculated. This allowed the calculation of intrapopulation diversity $\left(V_{S}\right)$, total diversity $\left(V_{\mathrm{T}}\right)$ and degree of substructure $\left(N_{\mathrm{ST}}\right)$ taking into account the degree of haplotype divergence (Pons \& Petit 1996). $G_{\mathrm{ST}}$ depends only on the frequencies of the haplotypes. However, $N_{\mathrm{ST}}$ is influenced by both haplotype frequencies and the distances between haplotypes. Statistical tests for departure of the parameter estimates from zero were performed by bootstrap resampling of populations.

\section{Analyses of spatial structure}

The spatial genetic software (SGS), developed by Degen et al. (2001), was used to perform a test on the geographical structure. For data sets with haplotype frequencies from different populations we selected a genetic distance measure, $D_{G}$ (Gregorius 1978), for calculation of genetic distance, $d_{i j}$, between the haplotype frequencies of the $i$ th and $j$ th populations. The estimate $d\left(s_{q}\right)$, representing the average genetic distance of all pairs of populations, were computed for pairs of data points belonging to a series of spatial distance classes $s_{q}$. This study permitted the assignment of all pairs to distance classes $\left(s_{q}\right)$ with class intervals of $22.5 \mathrm{~km}$. The dissimilarity of each pair of populations is calculated as (Degen \& Scholz 1998):

$$
\begin{aligned}
& d_{i j}=D_{G}(i, j)=\frac{1}{2} \sum_{k=1}^{n}\left|p_{i k}-p_{j k}\right| \\
& d\left(S_{q}\right)=\frac{1}{N_{q}} \sum_{i=1}^{N_{q}-1} \sum_{j=i+1}^{N} d_{i j}
\end{aligned}
$$

where $i$ and $j$ represent two populations, $n$ is the number of haplotypes and $p_{i k}$ is the relative frequency of the $k$ th haplotype. The plots of the calculated statistic are as a function of interpoint distance. A permutation procedure (resampling without replacement) was employed to test significant deviation from spatial random distribution.

\section{Results}

\section{Sequence analysis}

A total of 15 polymorphic sites were detected within the three sequenced cpDNA intergenic spacer fragments (Table 3). Among them, 12 sites were caused by point mutation and three were results of insertions. The 831-bp $\operatorname{trn} \mathrm{T}-\operatorname{trn} \mathrm{L}$ fragment consists of seven point mutations and three insertions, especially a 21-bp insertion occurring only on the eastern side of the CMR (GenBank accession no. AY091653, AY091654, AY091655, AY091656, AY091657, AY091658, AY091659, AY091660, AY091661, AY091662). Of the 811-bp comprising the $t r n \mathrm{~V}$ intron and the spacer of $t r n \mathrm{~V}$-trn $\mathrm{M}$ fragment, only two point mutations were detected in the intron (GenBank accession no. AY091650, AY091651, AY091652). Three point mutations were detected within the 319-bp petG-trnP fragment (excluding the trnW gene sequence) (GenBank accession no. AY091646, 
Table 3 Distribution of informative polymorphic sites in the intergenic spacers of cpDNA of Cyclobalanopsis glauca

\begin{tabular}{|c|c|c|c|c|c|c|c|c|c|c|c|c|c|c|c|}
\hline Haplotype & trnT 189 & $310-i 21$ & 336 & $403-i 6$ & $426-i 1$ & 531 & 563 & 615 & 619 & 728 & $\begin{array}{l}\operatorname{trn} \mathrm{V} \\
297\end{array}$ & 304 & $\begin{array}{l}\text { petG } \\
11\end{array}$ & 67 & 191 \\
\hline A & G & ----------------------- & $\mathrm{C}$ & ------ & - & $\mathrm{T}$ & G & G & $\mathrm{C}$ & G & G & $\mathrm{T}$ & G & G & G \\
\hline B & G & --------------------- & C & ----- & - & $\mathrm{T}$ & G & G & $\mathrm{C}$ & G & G & $\mathrm{T}$ & G & A & G \\
\hline $\mathrm{C}$ & G & -------------------- & $\mathrm{C}$ & ----- & - & $\mathrm{C}$ & G & G & $\mathrm{C}$ & G & G & $\mathrm{T}$ & G & A & G \\
\hline D & G & TAGAAATTAATAGAATAATAT & $\mathrm{C}$ & ------ & A & $\mathrm{T}$ & G & G & $\mathrm{C}$ & G & $\mathrm{C}$ & $\mathrm{T}$ & G & A & G \\
\hline $\mathrm{E}$ & G & ---------------------- & $\mathrm{C}$ & ------ & - & $\mathrm{T}$ & G & G & $\mathrm{C}$ & G & G & $\mathrm{T}$ & G & A & $\mathrm{T}$ \\
\hline $\mathrm{F}$ & $\mathrm{G}$ & ---------------------- & $\mathrm{C}$ & ------ & - & $\mathrm{T}$ & A & G & $\mathrm{C}$ & G & G & $\mathrm{T}$ & G & G & G \\
\hline G & A & -- & $\mathrm{C}$ & ------ & - & $\mathrm{T}$ & G & G & $\mathrm{C}$ & G & G & $\mathrm{C}$ & G & G & G \\
\hline $\mathrm{H}$ & G & ----------------------- & $\mathrm{C}$ & ------ & - & $\mathrm{T}$ & G & G & $\mathrm{C}$ & G & G & $\mathrm{T}$ & A & G & G \\
\hline I & G & -------------------- & A & ----- & - & $\mathrm{T}$ & G & G & $\mathrm{C}$ & G & G & $\mathrm{T}$ & G & G & G \\
\hline $\mathrm{J}$ & G & --- & $\mathrm{C}$ & ------ & - & $\mathrm{T}$ & G & G & $\mathrm{C}$ & A & G & $\mathrm{T}$ & G & G & G \\
\hline K & G & --------- & $\mathrm{C}$ & ------ & - & $\mathrm{T}$ & G & G & $\mathrm{T}$ & G & G & $\mathrm{T}$ & G & G & G \\
\hline $\mathrm{L}$ & $\mathrm{G}$ & --------------------- & $\mathrm{C}$ & TAAAAG & - & $\mathrm{T}$ & G & G & $\mathrm{C}$ & G & G & $\mathrm{T}$ & G & G & G \\
\hline M & G & ---------------------- & $\mathrm{C}$ & ------ & - & $\mathrm{T}$ & G & A & C & $\mathrm{G}$ & $\mathrm{G}$ & $\mathrm{T}$ & G & G & G \\
\hline
\end{tabular}

AY091647, AY091648, AY091649). The population of Castanopsis carlesii, sometimes occurring with C. glauca in their native habitat, was also included for sequence analysis, and the result showed several distinguishable sequences between these two species (data not shown). A preliminary observation indicates no evidence of introgression.

Four polymorphic sites (297 bp of trnV-trnM, 310-i21, 426-i1, and $563 \mathrm{bp}$ of $\operatorname{trn} \mathrm{T}-\mathrm{trn} \mathrm{L}$ ) exist only in the eastern populations. Two variations at 297 and $304 \mathrm{bp}$ in the $t r n \mathrm{~V}$ intron are associated with variations at 310-i21 and 426-i1, and $189 \mathrm{bp}$ in the $\operatorname{trnT}-\operatorname{tr} \mathrm{L} \mathrm{L}$ fragment, respectively, in the same individuals. The former variation was found in Suao (population no. 18, Table 1), Lungchien (no. 19), Wanjung (no. 20) and Yuli (no. 21) populations; while the latter was found in Yangmingshan (no. 1) and Pinglin (no. 2) populations. Five mutations are rare (191 bp of petG-trnP; $336 \mathrm{bp}$, 403-i6bp, $615 \mathrm{bp}$, and $728 \mathrm{bp}$ of $\operatorname{trn} \mathrm{T}-\operatorname{trn} \mathrm{L}$ ) and occur in only one individual each. To verify these singletons, we again synthesized and sequenced the fragments. The results showed exactly the same single nucleotide changes in five individuals. Another two mutations (11 bp of petG-trnP, and $619 \mathrm{bp}$ of $\operatorname{trn} \mathrm{T}-\mathrm{trn \textrm {L }}$ ) are also rare and limited to one population each.

Using the TCS program, 13 cpDNA haplotypes could be distinguished from the 15 polymorphic sites (Fig. 2). These haplotypes were assigned the letter codes A-M. The distribution of the observed haplotypes in each population is indicated in Table 1 and Fig. 1. Among the 13 haplotypes, two ancestral haplotypes (coded A and B) occur widely in Taiwan and Japan. Only haplotype A was observed in the two populations of the Ryukyus (nos 31, 32), Hong Kong (no. 30) and the only population (Guangdong, no. 29) available from Mainland China. Haplotype B probably also exists on the mainland, but the sample size was too small to be detected. This indicates that at least two haplotypes existed when the landmasses of Taiwan and Asia mainland

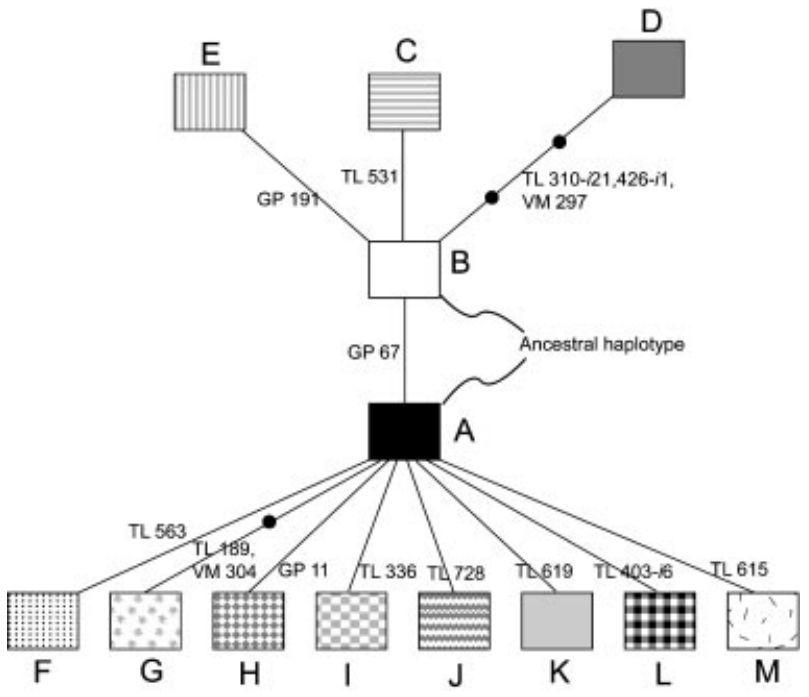

Fig. 2 The genealogical relationships between haplotypes of Cyclobalanopsis glauca are based on intergenic spacer of chloroplast genome (primer pairs: trnT/trnL, trnV/trnM and petG/trnP). Each line between haplotypes represents a mutational step, with numbers on lines indicating the variable base pair position. Insertion (i) relative to the centre of the tree is indicated after the base pair number, followed by the number of bases involved. Codes (A-M) for haplotypes are presented. TCS software was used in this analysis.

were connected. Haplotypes D and F are synapomorphies and can be found only on the eastern side of the CMR. The other nine haplotypes (C, E, G, H, I, J, K, L and M) were all rare and present in only one population or restricted to two neighbouring geographical locations. Three separated populations in the west of Taiwan, Yangmingshan (no. 1), Wushe (no. 10) and Chinshuiying (no. 16), consist of many haplotypes, but haplotypes in each population are all derived from the same ancestral one. Within the Wushe 
2354 S. S. F. HUANG, S.-Y. HWANG and T.-P. LIN

Table 4 Estimates of haplotype diversity $(h)$ and nucleotide diversity $(\pi)$ and test statistics of selection

\begin{tabular}{lllllll}
\hline Region & $\begin{array}{l}\text { No. of } \\
\text { populations }\end{array}$ & $\begin{array}{l}\text { No. of } \\
\text { haplotypes }\end{array}$ & $h$ & $\pi$ & $D$ & $D^{*}$ \\
\hline Total & 32 & 13 & 0.681 & 0.00065 & & \\
East Asia excl. Taiwan & 7 & 2 & 0.344 & 0.00018 & & $-2.52147+$ \\
Taiwan & 25 & 13 & 0.733 & 0.00074 & $-1.91688^{*}$ & $-2.69587+$ \\
West of CMR & 16 & 9 & 0.652 & 0.00051 & & \\
East of CMR & 12 & 7 & 0.795 & 0.000100 & & \\
\hline
\end{tabular}

$D$, Tajima's $D$-test; $D^{*}, \mathrm{Fu}$ and $\mathrm{Li}^{\prime}$ s test; $F^{*}, \mathrm{Fu}$ and Li's test. ${ }^{*} P<0.05 ;+P<0.02$.

population (no. 10), both haplotypes $\mathrm{C}$ and E mutated from B independently; while within the Chinshuiying population (no. 16) haplotypes $\mathrm{H}, \mathrm{I}$ and $\mathrm{J}$ are all derived independently from $\mathrm{A}$. The resulting gene tree suggests that haplotypes $\mathrm{C}$ and $\mathrm{E}$ (in Wushe, no. 10 and Huisun, no. 9) and hapotype D were all derived independently from haplotype B, and were related distantly to the remaining haplotypes, which all derived from haplotype A. In terms of haplotype diversity $(h)$ and nucleotide diversity $(\pi)$, east of the CMR has the highest values and both parameters decline in the direction of west of the CMR and East Asia, excluding Taiwan (Table 4). Overall, according to the 13 DNA sequences (1964 bp) the variation in three fragments deviated significantly to expectations of neutrality, both by Tajima's criterion $(D=-1.91688, P<0.05)$ and Fu and Li's test $\left(D^{*}=-2.52147, P<0.02 ; F^{*}=-2.69587\right.$, $P<0.02$ ) (Table 4).

\section{Analyses of population substructure}

Population differentiation, based on frequencies and the degree of haplotype divergence of the 25 Taiwan populations was 0.603 and 0.564 for $G_{\mathrm{ST}}$ and $N_{\mathrm{ST}}$, respectively (Table 5). Both $G_{\mathrm{ST}}$ and $N_{\mathrm{ST}}$ estimate the relative

Table 5 Analysis of population substructure of Cyclobalanopsis glauca in Taiwan

\begin{tabular}{llll}
\hline $\begin{array}{l}\text { Diversity } \\
\text { parameter }\end{array}$ & $\begin{array}{l}\text { Total } 25 \\
\text { populations }\end{array}$ & West of CMR & East of CMRt \\
\hline$H_{\mathrm{S}}$ & $0.285(0.0589)$ & $0.206(0.0795)$ & $0.303(0.0899)$ \\
$H_{\mathrm{T}}$ & $0.718(0.0683)$ & $0.623(0.1097)$ & $0.809(0.0809)$ \\
$G_{\mathrm{ST}}$ & $0.603(0.0781)$ & $0.669(0.1232)$ & $0.625(0.1129)$ \\
$V_{\mathrm{S}}$ & $0.232(0.0627)$ & $0.112(0.0483)$ & $0.342(0.1223)$ \\
$V_{\mathrm{T}}$ & $0.533(0.1054)$ & $0.354(0.0852)$ & $0.735(0.1621)$ \\
$N_{\mathrm{ST}}$ & $0.564(0.1116)$ & $0.682(0.1265)$ & $0.535(0.1749)$ \\
$N_{\mathrm{ST}}-G_{\mathrm{ST}}$ & -0.039 & 0.013 & $-0.090 \ddagger$ \\
\hline
\end{tabular}

*Includes populations 3, 4, 5, 6, 7, 8, 9, 10, 11, 12, 13, 14, 15, 16 and 17. tIncludes populations 1, 2, 3, 5, 18, 19, 20, 21, 22 and 25.

$\ddagger$ Indicates significantly different from zero at the $P<0.01$ level. proportion of the total genetic variation attributed to interpopulation variation, and indicated a significant degree of genetic structure of cpDNA variations. The $N_{\mathrm{ST}}$ value obtained from the Taiwan populations is smaller than the $G_{\mathrm{ST}}$ value; the value of $N_{\mathrm{ST}}-G_{\mathrm{ST}}(-0.039)$ was not significantly different from zero. When the populations were divided into two groups separated by the CMR, the value of $N_{\mathrm{ST}}-G_{\mathrm{ST}}$ was 0.013 for the western populations, and -0.090 for the eastern populations (Table 5). The former is positive and did not deviate significantly from zero, while the latter is negative and differed significantly from zero. Thus, at the local scale, there was a minor and insignificant tendency for haplotypes that were less divergent than average to co-occur in the same populations to the west of the CMR. Nevertheless, the phylogeographical component of the genetic structure is significant east of the CMR.

\section{Analyses of spatial structure}

SGS analysis using pairwise differentiation measures indicates that no genetic structure was detected in the Taiwan populations (Fig. 3a) or in the 19 populations excluding the six eastern ones: populations 19, 20, 21, 22, 23 and 24 of the CMR (Fig. 3b). Nevertheless the spatial distribution of the 18 eastern populations excluding the seven western ones: populations $7,8,9,10,11,12$ and 13 revealed clear geographical structure because the distogram of spatial structure deviates from the pattern of random distribution expected (Fig. 3c). The genetic distances increase with increasing geographical distance in the lower distance classes, but then decrease, and cross the $x$-axis at about $80 \mathrm{~km}$ and $200 \mathrm{~km}$, respectively.

\section{Discussion}

Isozyme data from a few widely distributed tree species in Taiwan suggested a glacial refugium in Nantou County, central Taiwan to the west of the CMR, because the highest expected heterozygosities occur coincidently in this area (Lin 2001). The highest expected heterozygosity in the 


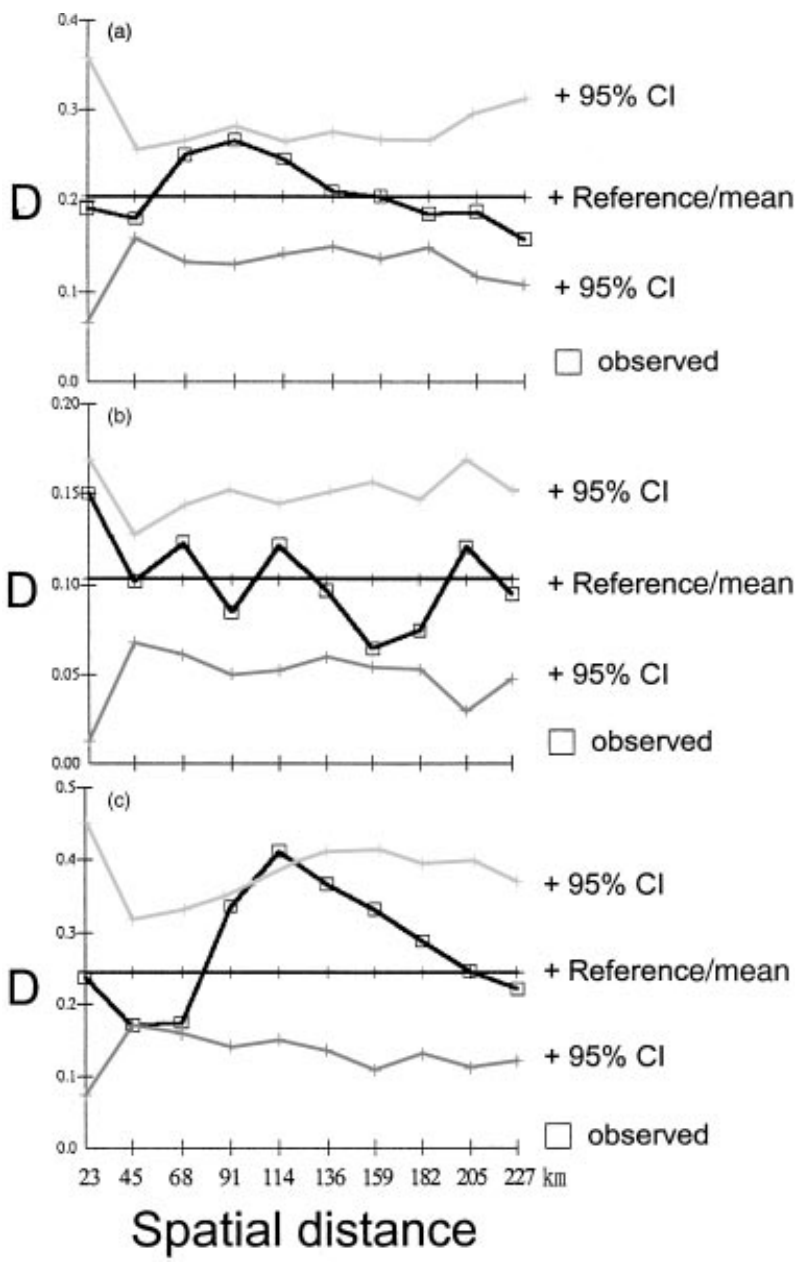

Fig. 3 Genetic distogram of genetic distances D in 10 geographical distance classes $(0-227 \mathrm{~km})$ in Taiwan. For the gene loci, 95\% confidence intervals of D (95\% CI) were computed by means of 1000 permutations over populations with redistributed geo-coordinates. (a) Spatial genetic structure analysis of 25 populations. (b) Genetic stucture analysis of 19 populations excluding the six eastern ones (population nos 19, 20, 21, 22, 23 and 24). (c) Analysis of 18 populations excluding the seven western ones (population $\operatorname{nos} 8,9,10,11,12$ and 13).

Nantou area is reinforced by the study on Trochodendron aralioides (Wu et al. 2001). In this study, cpDNA variations of Cyclobalanopsis glauca show three areas with the highest diversity: Yangmingshan (no. 1), Wushe (no. 10, in Nantou County) and Chinshuiying (no. 16), located in northern, central and southern Taiwan, respectively. They, however, exhibited autapomorphic variations not found in other areas. If Nantou County was the glacial refugium, we predicted a serious founder effect during postglacial recolonization. An early-arriving haplotype, assuming its origination from the refugium, could expand into suitable habitats, reducing the chances for establishment of subsequent arriving haplotypes. According to genealogy, however, two of three haplotypes in Wushe (no. 10) derived from the same ancestral haplotype, i.e. the haplotypes present within the population are sister lineages. They probably represent de novo mutation after the last glaciation. However, if they were more distantly related, lineage sorting would be the more appropriate explanation. This suggests that mutations in Wushe (no. 10) might occur after postglacial recolonization, contradicting the hypothesis of a refugium. Autapomorphic variations revealed that these three areas are ecologically very special in accumulating mutations. Thus, Yangminshan (no. 1), Wushe (no. 10) and Chinshuiying (no. 16) offer little evidence of colonization history in the west of CMR. Moreover, the pollen record from a lake core at an altitude of $745.5 \mathrm{~m}$ in central Taiwan suggested that the temperature during the maximal last glacial stage was $8.0-11.0^{\circ} \mathrm{C}$ cooler than today, and the lowland vegetation was dominated by the cooltemperate species (Tsukada 1966). Therefore, C. glauca, a warm-temperate species, could be scarce or extinct in central Taiwan at that time. Migration of C. glauca to southern Taiwan is expected. However, the concept of refugium can be investigated further only when more complete data on isozyme variation become available.

The CMR, consisting of numerous peaks higher than $3000 \mathrm{~m}$, runs from the north to the south (Fig. 1). Because C. glauca occurs in altitudes lower than $1700 \mathrm{~m}$, it is possible that the CMR has effectively interrupted gene flow between populations on both sides. A similar spatial pattern was found in several animal species, for example Rana limnocharis (Toda et al. 1998) and Callosciurus erythraeus (unpublished, pers. comm., Dr L.K. Lin). Eastern populations revealed substantial genetic differentiation from the remaining populations within Taiwan, and the genetic differentiation between them reflected the primary interruption of gene flow between the eastern and western Taiwan by the CMR and Hsuishan Mountain Range.

Haplotypes D and F are synapomorphies, and can be found only on the eastern side of the CMR. These haplotypes have the highest frequencies at Lungchien (no. 19) and Yuli (no. 21), respectively, and decreased in frequencies gradually in both the north and south populations. These haplotypes were probably originated from the eastern part of Taiwan, but they are not closely related genealogically. Together with the highest haplotype and nucleotide diversities (Table 4), this observation favours the concept of regarding the southeastern part of Taiwan as a potential refugium during the last glaciation. Haplotype $\mathrm{D}$ (terminal position) has three mutational steps more than haplotype B away from the ancestral haplotype A. Taking the mutation rate of cpDNA into account, the missing haplotypes occurred before the terminal haplotype could have been generated before the last glaciation.

The recolonization events of the Fuli-Tungho (no. 24) and Juisui-Takangkou (no. 23) populations along the 
Eastern Coastal Range seem to be independent of the populations of the eastern side of the CMR. The sampling site of the above two populations covered both the east and west sides of the Eastern Coastal Range. This distribution of haplotypes may be the result of founder effects of populations from the south.

A significant genetic structure is detected on the eastern side, but not on the western side (Fig. 3). This implies that patchy distributions occurred after recolonization in the east, and the patch sizes are about $80 \mathrm{~km}$ to $120 \mathrm{~km}$, matching perfectly the north-south range of haplotypes $\mathrm{D}$ and $\mathrm{F}$ and the remaining areas. This clear geographical structure in east Taiwan suggests little disturbance as a result of homoplasy and that specific haplotypes may be indicative of postglacial recolonization pathways. Within the patch, the genetic distances are smaller as the result of a homogenizing effect of recolonization from the same haplotypes. Among the patch, the genetic distances are increasing due to the recolonization from different haplotypes.

It is interesting to find that the difference between estimates $G_{\mathrm{ST}}$ and $N_{\mathrm{ST}}$ of populations is insignificant in the west of the CMR, but significant in the east. This implies that the relative geographical distribution of haplotypes has nothing to do with their genetic distances in the cases of old lineages that have had ample time to become geographically redistributed since they first appeared through mutations (Pons \& Petit 1996). As $N_{\mathrm{ST}}$ is sensitive to the different nucleotides between the two sequences, it will decrease when the unrelated haplotypes are found in the same population (Pons \& Petit 1996). The strongly unrelated haplotypes are found together much less often within the same population than related ones on the west side of the CMR. Strong human impact, such as civilization and cultivation, may have influenced the haplotype diversity and recolonization (Dumolin-Lapegue et al. 1997; Fineschi et al. 2000). Even C. glauca was used by aboriginal tribes, and only limited man-made plantations existed in selected sites. We consider that land overexploitation in the west of Taiwan, but much delayed in development in the east, probably plays little role in causing such different observations presented in Table 5.

Strangely enough, no ancestral type has been found in Huisun (no. 9) population. Similarly, no ancestral haplotype was found in Tayuanshan (no. 5), Lungchien (no. 19), Wanjung (no. 20) and Yuli (no. 21) populations, all located east of the CMR in conjunctive populations. To replace the standard sequence in the oaks throughout these regions would require strong selection or genetic drift. Because chloroplastic noncoding regions have no selective value, genetic drift is the only consequence to explain the resulting distribution of haplotypes. Given that genetic drift could be strong, it would still require a high level of dispersal. This seems unlikely for oaks. A founder effect in addition to drift would be a possible explanation. Once such populations are established, invasion from dispersants of another haplotypes would be difficult.

Evolutionary process leaves a signature in the 'star-like' phylogeny (Fig. 2) similar to what has been described (Page \& Holmes 1998). This genealogy is characterized by a very short depth and with very little branching structure near the root, where all the haplotypes coalesce rapidly. This means that there will have been insufficient time to produce a more structured population, and is actually a general outcome of population expansion. A neutrality test (Table 4) also suggested a demographic expansion and genotypes carrying the less common alleles are favoured (Hartl 2000). If the hypothesis that the southeastern part of Taiwan as a potential refugium in the last glaciation is correct, the population went through a bottleneck, also removing much pre-existing genetic variation, and has expanded northwards.

Across the species range, cpDNA variation in terms of nucleotide and haplotype diversities in Taiwan far exceeds the variations found in Japan, Hong Kong, Mainland China and the Ryukyus (Table 4). The cpDNA variation we see today must have been generated (in a geological time) when Taiwan became separated from the mainland. We suggest that differentiation between Taiwan and the Ryukyus and Mainland China populations occurred when sea levels rose during the interglacial stage to break up the land bridge. Taiwan, in the late Pleistocene, was thought to be connected to the Asian continent during the glacial maximum (Boggs et al. 1979). A more recent land configuration proposed for the late Pleistocene (0.2-0.02 Ma) indicates a large land bridge extended from eastern China to Taiwan, the Ryukyus and probably to the main islands of Japan (Kimura 1996), and should have made a great contribution by providing haplotypes with the opportunity of gene flow through the land bridge. Thus, all the cpDNA variation found in C. glauca would probably have evolved after the end of the last glaciation, c. 20000 years ago. The haplotypes of eastern Taiwan could also have originated in a much earlier geological time, but were trapped during the interglacial stage because of the barrier of the CMR.

Why does such an astonishing contrast in evolution occur in Okinawa and Taiwan, the same archipelago considered geologically to be of continental origin? They are significantly different in mountain deposition. With 30\% of Taiwan undulating strongly between 1000 and $3000 \mathrm{~m}$ above sea level, and peaks above $3000 \mathrm{~m}$ in elevation amounting to more than 200 in number, all located within the 'Central Range', this is in great contrast with low hills not more than $500 \mathrm{~m}$ in elevation found in the Ryukyus. A similar observation has been found for Cunninghamia lanceolata var. konishii, a temperate conifer variety endemic to Taiwan, where 15 cpDNA haplotypes have been found that are apparently derived from one common ancestral 
haplotype, but 11 derived haplotypes of C. lanceolata which are native to Mainland China (Hwang et al. unpublished data). With such a topography, Taiwan is able to accumulate more mutations than other areas.

\section{Acknowledgements}

This work was supported by a grant from the National Science Council, Taiwan under NSC 89-2313-B-002-254. The authors would like to thank Prof Bor-Hung Sheu, Department of Forestry, National Chung-Hsin University (population Huisun); Mr Tao Mo (population Hong Kong); Prof Yu-Feng Hsu, Department of Biology, National Taiwan Normal University (population GuangDong); Dr Inokura Youji, Takakuma Experimental Forest, Kagoshima University (population Kagoshima); Hideo Setsu, Kyushu University (population Kyushu); Mrs Masataka Higa and Makoto Hirata, Okinawa Forestry Research Institute, Okinawa Pref. (populations central and south Ryukyus). We also thank Drs Gwo-Shyong Hwang (population Kyoto), Yu-Chang Su, ChingTe Chien (population Wutai), Tsai-Huei Chen and Mrs Yu-Pin Cheng (populations Yangmingshan and Wushe) and Kuo-Chang Chen (population Liukuei), Taiwan Forestry Research Institute, for their kind help in sample collection.

\section{References}

Avise JC (1994) Molecular Markers, Natural History and Evolution. Chapman \& Hall, New York.

Boggs S, Wang WC, Lewis FS, Chen JC (1979) Sediment properties and water characteristics of the Taiwan shelf and slope. Acta Oceanographica Taiwanica, 10, 10-49.

Chiang TY, Chiang YC, Chen YJ, Chou CH, Havanond S, Hong TN, Huang S (2001) Phylogeography of Kandelia candel in East Asiatic mangroves based on nucleotide variation of chloroplast and mitochondrial DNAs. Molecular Ecology, 10, 2697-2710.

Degen B, Petit RJ, Kremer A (2001) SGS - spatial genetic software: a computer program for analysis of spatial genetic and phenotypic structure of individuals and populations. Journal of Heredity, 92, 447-449.

Degen B, Scholz F (1998) Spatial genetics differentiation among populations of European beech (Fagus sylvatica L.) in western Germany as identified by geostatistical analysis. Forest Genetics, 5, 191-199.

Dow BD, Ashley MV (1996) Microsatellite analysis of seed dispersal and parentage of saplings in bur oak, Quercus macrocarpa. Molecular Ecology, 5, 615-627.

Dumolin-Lapegue S, Demesure B, Fineschi S, Corre VLE, Petit RJ (1997) Phylogeographic structure of white oaks throughout the European cotinent. Genetics, 146, 1475-1487.

Ferris C, King RA, Vainola R, Hewitt GM (1998) Chloroplast DNA recognizes three refugial sources of European oaks and suggests independent eastern and western immigrations to Finland. Heredity, 80, 584-593.

Ferris C, Oliver RP, Davy AJ, Hewitt GM (1995) Using chloroplast DNA to trace postglacial migration routes of oaks into Britain. Molecular Ecology, 4, 731-738.

Fineschi S, Taurchini D, Villani F, Vendramin GG (2000) Chloroplast DNA polymorphism reveals little geographical structure in Castanea sativa Mill. (Fagaceae) throughout southern European countries. Molecular Ecology, 9, 1495-1503.
Gregorius HR (1978) The concept of genetic diversity and its formal relationship to heterozygosity and genetic distance. Mathematical Biosciences, 41, 253-271.

Hare MP (2001) Prospects for nuclear gene phylogeography. TRENDS in Ecology and Evolution, 16, 700-706.

Hartl DL (2000) A Primer of Population Genetics, 3rd edn. Sinauer Associates, Inc, Sunderland, MA.

Hsieh CF, Shen CF, Yang KC (1994) Introduction to the flora of Taiwan, 3. Floristics, phytogeography, and vegetation. In: Flora of Taiwan (eds Editorial Committee of the Flora of Taiwan), 2nd edn, vol. 1, pp.7-18. Editorial Committee of the Flora of Taiwan, Taipei, Taiwan.

Hsu FH, Lin FJ, Lin YS (2000) Phylogeographic structure of the formosan wood mouse, Apodemus semotus Thomas. Zoological Studies, 40, 91-102.

Hsu FH, Lin FJ, Lin YS (2001) Phylogeographic variation in mitochondrial DNA of formosan white-bellied rat Niviventr culturatus. Zoological Studies, 39, 38-46.

Huang S, Chiang YC, Schaal BA, Chou CH, Chiang TY (2001) Organelle DNA phylogeography of Cycas taitungensis, a relict species in Taiwan. Molecular Ecology, 10, 2669-2681.

Hwang LH, Hwang SY, Lin TP (2000) Low chloroplast DNA variation and population differentiation of Chamaecypaeis formosensis and Chamaecyparis taiwanensis. Taiwan Journal of Forest Science, 15, 229-236.

Kimura M (1996) Quaterary paleogeography of the Ryukyu arc. Journal of Geography, 105, 259-285 [in Japanese with English abstract].

Lin TP (2001) Allozyme variations in Michelia formosana (Kanehira) Masamune (Magnoliaceae), and the inference of a glacial refugium in Taiwan. Theoretical and Applied Genetics, 102, 450457.

Lu SY, Peng CI, Cheng YP, Hong KH, Chiang TY (2001) Chloroplast DNA phylogeography of Cunninghamia konishii (Cupressaceae), an endemic conifer of Taiwan. Genome, 44, 797-807.

Matyas G, Sperisen C (2001) Chloroplast DNA polymorphism provide evidence for postglacial re-colonisation of oaks (Quercus spp.) across the Swiss Alps. Theoretical and Applied Genetics, 102, 12-20.

McCauley DE (1995) The use of chloroplast DNA polymorphism in studies of gene flow in plants. Trends in Ecology and Evolution, 10, 198-202.

Murray MG, Thompson WF (1980) Rapid isolation of high molecular weight plant DNA. Nucleic Acids Research, 8, 4321-4325.

Pages RDM, Holmes E (1998) Molecular Evolution, Aphylogenetic Approach. Blackwell Science Ltd, Oxford.

Pons O, Petit RJ (1995) Estimation, variance and optimal sampling of gene diversity. I. Haploid locus. Theoretical and A pplied Genetics, 90, 462-470.

Pons O, Petit RJ (1996) Measuring and testing genetic differentiation with ordered versus unordered alleles. Genetics, 144, 1237-1245.

Rozas J, Rozas R (1999) Dnasp, version 3: an integrated program for molecular population genetics and molecular evolution analysis. Bioinformatics Application Note, 15, 174-175.

Taberlet P, Gielly L, Pautou G, Bouvet J (1991) Universal primers for amplification of three non-coding regions of chloroplast DNA. Plant Molecular Biology, 17, 1105-1109.

Templeton AR, Crandall KA, Sing CF (1992) A cladistic analysis of phenotypic associations with haplotypes inferred from restriction endonuclease mapping and DNA sequence data. III. Cladogram estimation. Genetics, 132, 619-633. 
2358 S. S. F. HUANG, S.-Y. HWANG and T.-P. LIN

Toda M, Nishida M, Matsui M, Lue KY, Ota H (1998) Genetic variation among populations of the Indian rice frog, Rana limnocharis (Amphibia: Anura) within Taiwan: revealed by allozyme data. Herpetologoca, 54, 73-82.

Tomaru N, Takahashi M, Tsumura Y, Takahashi M, Ohba K (1998)

Intraspecific variation and phylogeographic patterns of Fagus crenata (Fagaceae) mitochondrial DNA. American Journal of Botany, 85, 629-636.

Tsukada M (1966) Late Pleistocene vegetation and climate in Taiwan
(Formosa). Proceedings of National Academy of Sciences of the United States of America, 55, 543-548.

Wu JE, Huang S, Wang JC, Tong WF (2001) Allozyme variation of Trochodendron aralioides, a monotypic and narrow geographic species. Journal of Plant Research, 114, 45-57.

Yang YJ, Lin YS, Wu JL, Hui CF (1994) Variation in mitochondrial DNA and population structure of the Taipei treefrog Rhacophorus taipeianus in Taiwan. Molecular Ecology, 3, 219228. 